\title{
Potential of Silty Clay Soil as an Attenuation Material for Containment of Phenolic Wastewater Outfall Site
}

\author{
Supriya Pal, Kalyan Adhikari, Somnath Mukherjee, and Sudipta Ghosh
}

\begin{abstract}
Use of compacted silty clay soil collected from the Gangetic river sediment near Kolkata, West Bengal, India has been experimentally explored in the laboratory as a low cost landfill liner material for retarding the migration of phenolic compounds releasing from a coke oven wastewater outfall site in Durgapur, West Bengal, India. The phenol concentration in the wastewater was found in the range of $4.0-12.0 \mathrm{mg} / \mathrm{L}$ in different times of a calendar year. Batch adsorption results reveal that the maximum phenol removal efficiency of $95 \%$ was achieved at an initial phenol concentration of $4 \mathrm{mg} / \mathrm{L}$ for the soil dose of $20 \mathrm{~g} / \mathrm{L}$, solution pH of 6.0 and after a reaction time of $24 \mathrm{~h}$. Index properties, swelling potential, compaction characteristics and permeability of the soil indicate that it is low compressible, moderately expansive and low permeable $\left(1.90 \times 10^{-8} \mathrm{~cm} / \mathrm{s}\right)$ and having reasonably good phenol attenuation capacity $(472.5$ $\mathrm{mg} / \mathrm{g}$ ). These favorable findings suggest that the compacted clay soil can be potentially utilized as primary landfill liner material for containment of phenolic waste generated from coke oven wastewater.
\end{abstract}

Index Terms-Attenuation, clayey soil, landfill liner, phenol.

\section{INTRODUCTION}

Compacted clay soils are widely used as a primary landfill liner for containment of hazardous and toxic waste in the waste dumping sites [1]-[3]. The containment facility in its simplest form consists of a clay liner, a cover and the waste [4]. Locally available natural clays can prove economical liner material provided it satisfies the standard specifications for design and construction of new waste containment structures [5]-[8]. The leakage from a landfill liner may cause lithosphere pollution due to migration of toxic leachates from the dumping waste and thereby pronounced severe adverse impact on the environment. The clay liner should not only have good contaminant attenuative potential, but also it should possess low permeability $\left(\leq 1 \times 10^{-7} \mathrm{~cm} / \mathrm{s}\right)$, compressibility and have adequate shear strength to resist bearing capacity and slope failure [5], [9], [10].

In the present work, laboratory studies were conducted to explore whether a typical silty clay soil obtained from the Gangetic river bed sediments near Kolkata, West Bengal, India can be utilized as landfill liner material. Typical tests

Manuscript received September 29, 2014; revised March 2, 2015.

Supriya Pal is with the Civil Engineering Department, National Institute of Technology Durgapur, West Bengal, India (e-mail: supriya.pal@ce.nitdgp.ac.in).

Kalyan Adhikari is with the Department of Earth and Environmental Studies, National Institute of Technology Durgapur, West Bengal, India (e-mail: k_adh@yahoo.co.in).

Somnath Mukherjee and Sudipta Ghosh are with the Civil Engineering Department, Jadavpur University, Kolkata, West Bengal, India (e-mail: snm_ju@yahoo.com,sghosh56@yahoo.com). generally used to assess the physico-chemical properties such as grain size distribution, Atterberg limits, swelling potential, permeability, triaxial shear strength, compaction characteristics etc. were conducted and analyzed for using it as liner material in waste containment structures.

\section{MATERIALS AND METHODS}

\section{A. Study Area}

The outfall or effluent discharge site of coke-oven wastewater from a steel plant industry in Waria (Fig. 1), Durgapur, west Bengal, India was considered as an experimental study area in the present investigation. Durgapur is known to be the industrial city of the state of West Bengal. The effluent is discharged in an unlined pit connected with a narrow drain which meets a natural storm water drain at a distance of approximately $100 \mathrm{~m}$ in the northwest. The storm water drain finally meets the Damodar River in the south. Most of the flow of the drain connected to the pit has been deliberately diverted to the open field for collection of suspended coal particles by the local people. This practice has rendered the groundwater of this zone more vulnerable due to stagnation of effluents covering a large surface area and permeable nature of the soil.

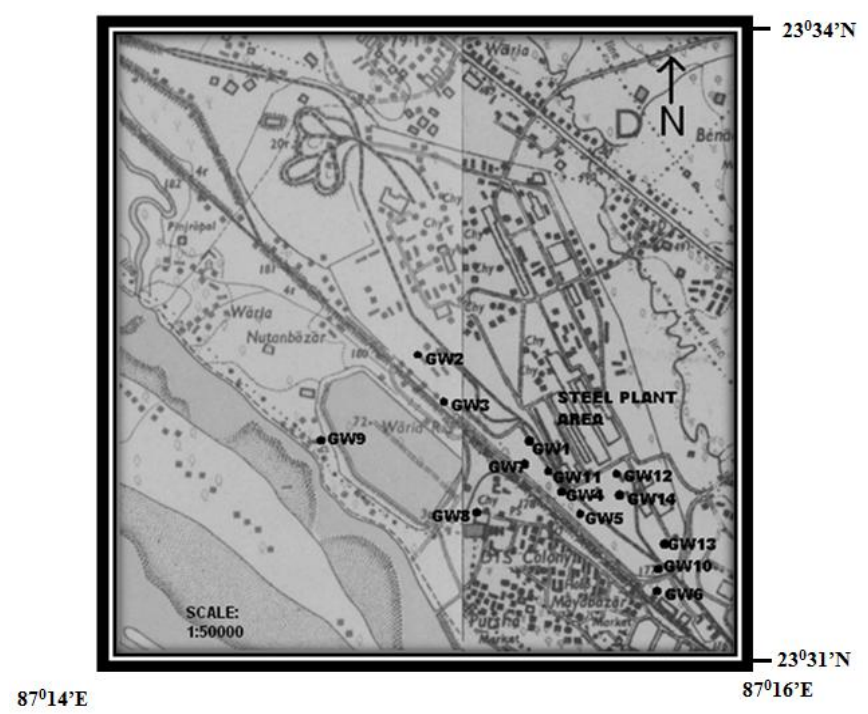

Fig. 1. Location of groundwater quality sampling stations. 'GW' stands for sampling points.

\section{B. Characterization of Groundwater and Wastewater in Outlet Pool near Coke-Oven Wastewater Discharge Site}

Groundwater and pit wastewater samples from coke-oven wastewater discharge site were collected at different times and tested according to 'Standard Methods' [11] for 
determination of different physicochemical parameters. An earlier study in this regard was carried out by the authors, and the existence of phenolic compound both in soil and groundwater was noticed in appreciable value which is high above the permissible limit [12]. The waste water from the discharge pool at the disposal site was found to contain $4.0-12.0 \mathrm{mg} / \mathrm{L}$ of phenol concentration after analyzing 20 nos. of samples at different times in a calendar year. The groundwater also had high concentration of phenol (1.25 $\mathrm{mg} / \mathrm{L})$ in the nearby area which exceeded the maximum permissible limit of phenol in drinking water is $0.002 \mathrm{mg} / \mathrm{L}$ [13].

Due to this alarming level of phenolic concentration in the open discharge area, phenol was used as a test contaminant in the present study.

\section{Soil as Liner Material}

The soil samples were collected from a soil quarry located in the Gangetic river bed sediments near Kolkata, West Bengal, India for exploring its potential of attenuation capacity against phenol movement from the effluent discharge site and furthermore to be used as liner material in the waste containment structure. The samples were brought to the Soil Mechanics and Foundation Engineering Laboratory of National Institute of Technology, Durgapur, West Bengal, India for determining the physico-chemical properties as per the guidelines given in Bureau of Indian Standards [14]-[21]. First, the soil was oven-dried at $100 \pm 20^{\circ} \mathrm{C}$ temperatures for $24 \mathrm{~h}$ for evaporating out the moisture content in it to dryness and then it was stored in desiccators until use. Some of the important soil parameters such as specific gravity, bulk density, grain size distribution, Atterberg limits, permeability, shear strength parameters, swelling potential, compaction characteristics, organic carbon content etc. were determined. The grain size distribution of soil was determined by hydrometer (Make-Testing Instruments Mfg. Co. Pvt. Ltd., India) and sieve analyses (Make- Geologists Syndicate Pvt. Ltd., India). The specific gravity, natural moisture content, liquid limit, and $\mathrm{pH}$ of soil was measured by pycnometer (Make-Testing Instruments Mfg. Co. Pvt. Ltd., India), Digital moisture meter (Model M-3A, make-Advance Research Instruments Co., India), Casagrande apparatus (Make-Aimil Ltd., India), and Digital pH meter (Model-pH 1100, make-EUTECH, Singapore), respectively.

Phenol was estimated by acid digestion of the soil sample with 1:9 phosphoric acid and aliquot was filtered followed by spectrometric analysis. No background phenol was traced in the soil samples that were used as liner material in the present study. The permeability of the soils were determined by falling head permeameter using following Eq. 1:

$$
K_{S}=2.303 \frac{a L}{A t} \log _{10} \frac{h_{1}}{h_{2}}
$$

where $K_{S}$ is the permeability $(\mathrm{cm} / \mathrm{s}), a$ is the cross sectional area of the stand pipe fitted over the permeameter $\left(\mathrm{cm}^{2}\right), L$ is the length of the standpipe of the soil sample $(\mathrm{cm}), \mathrm{A}$ is the total cross sectional area of the soil sample $\left(\mathrm{cm}^{2}\right), t$ is time (sec), $h_{1}$ and $h_{2}$ are the head of water in $\mathrm{cm}$ in the stand pipe at two chosen time intervals $t_{1}$ and $t_{2}$.

\section{Triaxial Shear Test}

Triaxial shear test was conducted on the soil specimens prepared by molding the soil to a dry density, $\rho_{d}=15.2 \mathrm{kN} / \mathrm{m}^{3}$ and moisture content, $w=19 \%$, which match the optimum condition of the studied soil. The test was conducted as per protocol laid down in code of practices of the Bureau of Indian Standard [22]. Consolidated undrained (CU) triaxial shear test were performed using four replicate samples under four confining pressures of 50,100, 150 and $200 \mathrm{kN} / \mathrm{m}^{2}$ respectively. The applied ratio of shear was $1.0 \mathrm{~mm} / \mathrm{min}$. To ensure repeatability of test results, the test was conducted in duplicate and average of the replicate test results was considered as the representative value of the shear strength parameters (cohesion, $c$ and angle of internal friction, $\varphi$ ) of the soil.

\section{E. Vertical Swelling Test}

The vertical swelling test was conducted on the remolded soil specimen at maximum dry density and optimum moisture content stated above. The soil specimen was inundated in the odeometer apparatus and allowed to swell vertically at a seating pressure of $1 \mathrm{kN} / \mathrm{m}^{2}$ as per the procedure described in the 'Standard Method' [23]. The test was conducted in duplicate with replicate samples and average value of the two test results was taken as the representative swell potential value. The amount of vertical swelling was calculated based on the following Eq. 2.

$$
S=\frac{L_{2}-L_{1}}{L_{1}} \times 100
$$

where, $S=$ percentage vertical swelling, $L_{1}=$ initial height of the soil sample in $\mathrm{mm}$ before application of water in odeometer, $L_{2}=$ final height of sample in $\mathrm{mm}$ after it had been allowed to swell in presence of water for $48 \mathrm{~h}$.

\section{F. Batch Adsorption Studies}

The batch adsorption tests were carried out by varying the adsorbate (phenol) concentrations at desired initial $\mathrm{pH}$ with a fixed amount of adsorbent. In this test, a 100-ml water sample containing desired concentrations of synthetically prepared phenol and $0.2 \mathrm{~g}$ of soil was kept in $250 \mathrm{ml}$ capacity conical flasks and stirred for $24 \mathrm{~h}$ in an orbital shaker at a speed of 150 $\mathrm{rpm}$. The supernatant solutions were filtered by Whatman 42 filter paper, and the residual phenol concentrations in the supernatant solutions were analyzed to calculate the amount of phenol retained in the solid phase, $q_{e}(\mathrm{mg} / \mathrm{g})$ by using the following Eq. 3.

$$
q_{e}=\frac{\left(c_{0}-c_{e}\right) V}{M}
$$

where $C_{0}$ and $C_{e}$ are the initial and equilibrium concentration of phenol in $\mathrm{mg} / \mathrm{L}, V=$ volume of solution in $\mathrm{ml}, M=$ mass of adsorbent in grams.

\section{G. Analysis of Phenol}

The phenol concentrations in water were determined in accordance with Standard Methods [11]. The residual phenol concentrations were determined spectrophotometrically after developing color using $0.3 \mathrm{ml}$ each of potassium ferricyanide and 4-amino antipyrine solution. The solution was then 
allowed to stand for 10-15 $\mathrm{min}$ for full color development. The concentrations of phenol were measured by UV-visible spectrophotometer at a wavelength of $500 \mathrm{~nm}$ in a $5 \mathrm{~cm}$ cell.

\section{RESULTS AND DISCUSSIONS}

\section{A. Soil Quality}

The soil characteristic parameters are exhibited in Table I. The grain size distribution shows that the soil contains $41 \%$ clay fraction $(<0.002 \mathrm{~mm})$, with $40 \%$ silt $(0.002$ to $0,075 \mathrm{~mm})$ and $19 \%$ sand $(0.075$ to $0.6 \mathrm{~mm})$. The Atterberg limits of the soil were: liquid limit (LL), 39.32\%; plastic limit (PL), $25.11 \%$; the plasticity index (PI=LL-PL), $14.21 \%$. The soil can be classified as CI (inorganic clay with intermediate plasticity) [24]. The shrinkage limit (Atterberg limit) of the soil found $20.67 \%$ from the laboratory test. This high shrinkage limit $(12 \%$ or more) value of the clay soil will reduce the shrinkage potential during the dry season and thereby minimizing the undesirable desiccation crack within the clay liner [25], [26]. The activity (the ratio of PI to the percent by weight of soil particles of diameter smaller than $0.002 \mathrm{~mm}$ ) of the soil is about 0.35 . The soil can be classified as inactive (activity<0.75) [27]. The soils with higher activity pronounced undesirable behavior such as higher compressibility, swelling and shrinkage characteristics and more likely affected by contaminants if used as liner materials in containment structures [27], [28].

However, literatures depict that soil with following index properties: percentage of clay (fraction smaller than 0.002 $\mathrm{mm}$ ) $\geq 20$ to $25 \%$, percentage of fines (fraction smaller than $0.075 \mathrm{~mm}) \geq 50 \%$, plasticity index $(\mathrm{PI}) \geq 12$ to $15 \%$ and activity $\geq 0.3$ may be considered as landfill liner materials in waste containment structures [26], [29], [30]. Based on the above criteria, it is observed that the studied soil complied the standards and requirements for using as landfill liner material.

TABLE I: PHYSICO-CHEMICAL PROPERTIES OF THE SOIL USED IN THE STUDY

\begin{tabular}{|l|l|}
\hline Physical properties & Clay soil \\
\hline Specific gravity & 2.34 \\
\hline Natural moisture content $(\%)$ & 32.23 \\
\hline Bulk density $\left(\mathrm{kN} / \mathrm{m}^{3}\right)$ & 14.1 \\
\hline Liquid limit $(\%)$ & 39.32 \\
\hline Plastic limit $(\%)$ & 25.11 \\
\hline Plasticity Index (\%) & 14.21 \\
\hline Activity, $A_{c}$ & 0.35 \\
\hline Shrinkage Limit $(\%)$ & 20.67 \\
\hline pH & 5.3 \\
\hline Maximum dry density $\left(\mathrm{kN} / \mathrm{m}^{3}\right)$ & 15.2 \\
\hline Optimum moisture content $(\%)$ & 19 \\
\hline Permeability $(\mathrm{cm} / \mathrm{s})$ & $1.90 \times 10^{-8}$ \\
\hline Organic carbon $(\%)$ & 3.65 \\
\hline Sand $(\%)$ & 19 \\
\hline Silt $(\%)$ & 40 \\
\hline Clay $(\%)$ & 41 \\
\hline Vertical swelling $(\%)$ & 6.26 \\
\hline
\end{tabular}

\section{B. Permeability Values of Laboratory Compacted Soil Samples}

The results of dry density and permeability values of the soil sample at different water contents are shown graphically in Fig. 2. The maximum dry density of about $15.2 \mathrm{kN} / \mathrm{m}^{3}$ was achieved at $19 \%$ water content. The dry density continues to increase in the soil specimen till the optimum moisture content was reached. The lubrication affect around the soil particles with the increment of water content makes them closure into a denser configuration, resulting in a higher dry density. At the optimum moisture content (OMC), the lubrication effect is the maximum. With further increase in water content, the dry density decreases as the water starts to replace the soil particles and density of water $\left(\gamma_{w}\right)$ is less than the density of solid $\left(\gamma_{s}\right)$. From Fig. 2 , it is observed that the permeability value decreases sharply with increase in water content on the dry side of the optimum. However, the lowest permeability of the compacted clay occurs at water content slightly (2\%) wet side of the optimum water content (19\%). Further increment of water content, slight increase in permeability is observed, but it always remains smaller than dry side of the optimum. The sharp decrease in permeability in dry side of the optimum with increase of water content was due to reorientation of soil particles and reduction of size of voids [30]-[32]. The compacted clay should have permeability at least $1 \times 10^{-7} \mathrm{~cm} / \mathrm{s}$ for using as liner material [1], [33]. The present soil met the permeability criterion on both dry and wet sides of the optimum water content. However, during construction of liner, the compaction of soil at water content wet side of optimum is not recommended because of other associated problems of slope instability caused by lower shear strength of the soil and operational problems with construction equipments on soft weak soil [25].

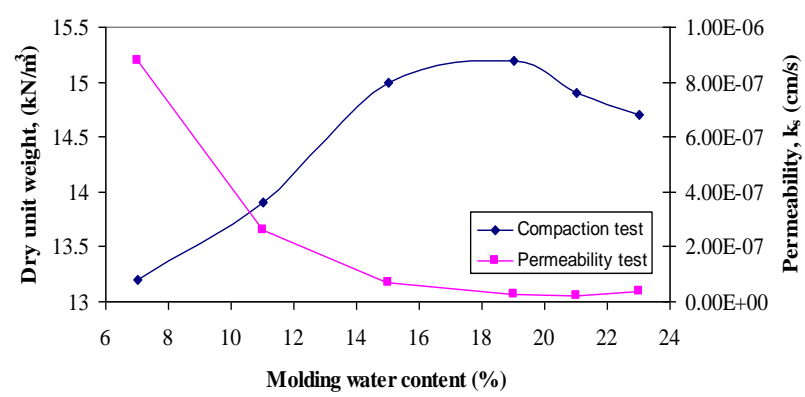

Fig. 2. Influence on permeability of the soil at different water content under Standard Proctor energy.

\section{Swelling Potential}

The vertical swelling potential of the clay soil was about $6.26 \%$. The swelling potential of the studied soil was low to moderate [25]. High swelling clays suffer from differential settlements and crack on drying. The cracks on liner surface leads to migration of contaminants into the soils and groundwater and thereby hampering the desired functions of liner systems [26], [34]. Therefore, the present soil with low swelling potential are found suitable for the construction of liners in containment structures.

\section{Shear Strength}

The liner materials should have adequate shear strength for maintaining the stability of the side slopes and also have safe bearing capacity against base shear failure [5]. The results of the shear strength parameters obtained from triaxial shear test 
for the studied soil are given in Table II and Fig. 3.

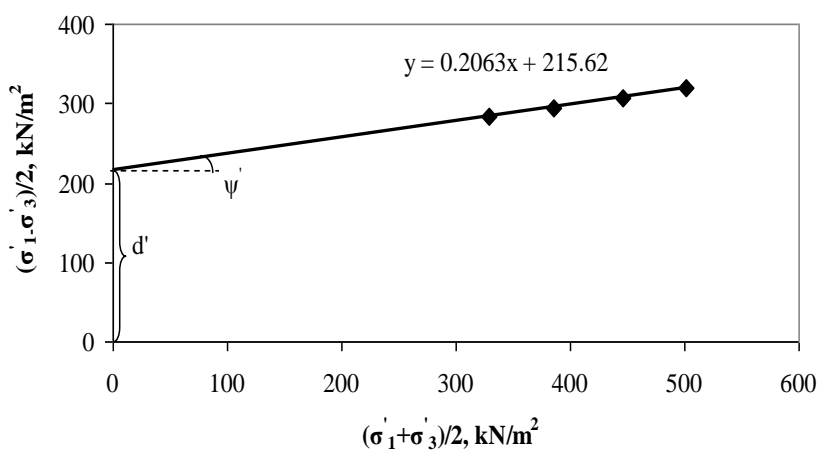

Fig. 3. Failure envelope of the soil in the CU triaxial shear test.

TABLE II: SHEAR STRENGTH PARAMETERS FOR THE SOIL

\begin{tabular}{ll}
\hline Cohesion $\mathrm{C}\left(\mathrm{kN} / \mathrm{m}^{2}\right)$ & Friction angle $\varphi(\mathrm{deg})$ \\
\hline 220 & 12 \\
\hline
\end{tabular}

According to Lambe [35], the slope $\psi^{\prime}$ and intercept $d^{\prime}$ in Fig. 3 are related to $c^{\prime}$ and $\varphi^{\prime}$ through Eq. 4.

$$
\operatorname{Sin} \varphi^{\prime}=\tan \psi^{\prime}
$$

and

$$
c^{\prime}=\frac{d^{\prime}}{\cos \phi^{\prime}}
$$

The shear strength of the soil was calculated based on following Eq. 5.

$$
\tau_{f}=c^{\prime}+\sigma \tan \varphi^{\prime}
$$

where, $\sigma=$ overburden pressure $\left(\mathrm{kN} / \mathrm{m}^{2}\right)$ of waste materials at the top of the soil liner, $\tau_{f}=$ shear strength of soil at failure $\left(\mathrm{kN} / \mathrm{m}^{2}\right)$.

$$
\sigma=\gamma_{\text {waste }} d
$$

where, $\gamma_{\text {waste }}=$ average unit weight of the waste material in $\mathrm{kN} / \mathrm{m}^{3}$ and $d=$ depth of waste materials above the top of the soil liner.

The shear strength of the remolded soil compacted at maximum dry density and optimum water content was found to vary with depth below ground surface as exhibited in Table III.

TABLE III: VARIATION OF SHEAR STRENGTH OF THE LINER DEPENDING UPON WASTE OVERBURDEN PRESSURE (ASSUMING UNIT WEIGHT OF

\begin{tabular}{lcc}
\multicolumn{3}{c}{ WASTEWATER $\left.=10 \mathrm{KN} / \mathrm{M}^{3}\right)$} \\
\hline $\begin{array}{c}\text { Depth of waste above } \\
\text { the soil liner }(\mathrm{m})\end{array}$ & $\begin{array}{c}\text { Overburden pressure } \\
\left(\mathrm{kN} / \mathrm{m}^{2}\right)\end{array}$ & $\begin{array}{c}\text { Shear strength } \\
\left(\mathrm{kN} / \mathrm{m}^{2}\right)\end{array}$ \\
\hline 1 & 10 & \\
2 & 20 & 222.12 \\
3 & 30 & 224.25 \\
\hline
\end{tabular}

Daniel and $\mathrm{Wu}$ [29] reported that the soil used as liner should have minimum shear strength of $200 \mathrm{kN} / \mathrm{m}^{2}$. Test results (Table III) show that the soil possesses higher shear strength than the recommended minimum shear strength for any depth below surface.

\section{E. Batch Adsorption Studies}

The batch adsorption results depicting the percentage removal of phenol against different initial concentrations of phenol solution and soil as adsorbent medium for a contact time of $24 \mathrm{~h}$ are shown graphically in Fig. 4. The $\mathrm{pH}$ of the soil solution mixtures were maintained at 6.0. Literatures reported that maximum phenol removal by soil occurred at solution pH 6.0. [36]-[38]. The study revealed that the increased removal percentage with increase of initial phenol concentrations from 0.5 to $4 \mathrm{mg} / \mathrm{L}$, accomplishing the maximum removal $(95.30 \%)$ at an initial concentration of 4 $\mathrm{mg} / \mathrm{L}$ and then found to be decreased marginally beyond it towards the initial phenol concentration of $10 \mathrm{mg} / \mathrm{L}$. As the initial concentrations of phenol increases, the higher amount of phenol was adsorbed on the surface of adsorbent due to higher concentration gradient, depending on active available sites according to its uptake capacity as well as the presence of amount of organic carbon in soil. The descending trend was obtained because of lesser diffusion and binding on the top of the soil surface due to exhaustion of active sites and for which reducing effect of phenol observation was noticed. Similar finding was reported earlier by Kiran and Chandrajit [39]. The maximum phenol uptake capacity of the soil was found $472.5 \mathrm{mg} / \mathrm{kg}$. Due to this reasonable uptake and attenuation capacity of the studied soil, it can be considered as a primary landfill liner for containment of phenolic waste in waste disposal sites.

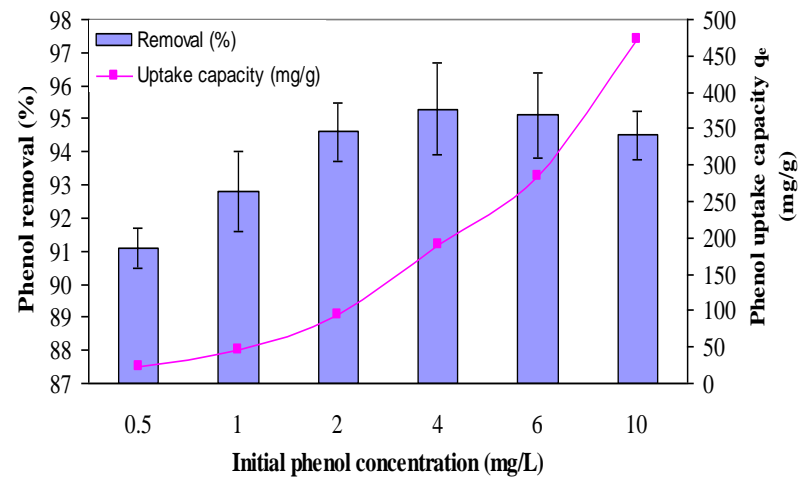

Fig. 4. Phenol removal percentage and uptake capacity as a function of initial phenol concentrations of the solution at adsorbent dose $=20 \mathrm{~g} / \mathrm{L}, \mathrm{pH}=6.0$ and contact time $=24$ hours. Vertical bars show standard deviation of three replicates.

\section{CONCLUSION}

1) Silty clay occurring in the Gangetic river basin near Kolkata, West Bengal are suitable as landfill liner materials for containment of phenolic wastewater generated from the phenol wastewater releasing industry.

2) The clays from the Gangetic river basin contain more than $40 \%$ of clay fraction and not more than $20 \%$ sand with $3.65 \%$ organic carbon content. According the liquid limit value (39\%) and plasticity index (14\%), these clays corresponds to CI (inorganic clay with intermediate plasticity) category.

3) The high shrinkage limit $(20.67>12 \%)$ and low activity $(<0.75)$ values of the clay materials not only reduces the chances of desiccation cracks in the dry season but also minimizes undesirable behavior such as higher compressibility, swelling and shrinkage characteristics and more likely affected by contaminants if used as liner materials in containment structures. The vertical swelling 
potential of the clay soil was about $6.26 \%$ which is considered as low to moderate.

4) The relationship between permeability and compaction parameters exhibit that the lowest permeability $\left(1.90 \times 10^{-8} \mathrm{~cm} / \mathrm{s}\right)$ was achieved at wet side of optimum water content $(19 \%)$ and which is well below the standard acceptable limit suggested by waste regulatory bodies for landfill liners to retard the subsurface migration of the contaminants. However, during construction of liner, the compaction of soil at higher water content causes slope instability due to lower shear strength as well as operational problems with construction equipments on soft weak soil. Hence, judicial selection of water content to compact the soil in the field is very important. In case of present soil, water content marginally dry side of the optimum may be chosen for the abovementioned purpose without negating the permeability requirements.

5) The adequate strength, good phenol attenuation capacity (472 mg/g), low susceptibility to shrinkage and swelling in addition to large areal extent of availability at reasonable hauling distance can make these soils as potential materials for compacted soil liners in waste containment structures. However, further laboratory and field testing should be conducted before accepting its potentiality to restrict the migration of contaminants.

\section{ACKNOWLEDGMENT}

The authors are thankful to the Director, National Institute of Technology Durgapur-713209, West Bengal, INDIA for providing necessary assistance for carrying out the present research.

\section{REFERENCES}

[1] I. Bozbey and E. Guler, "Laboratory and field testing for utilization of an excavated soil as landfill liner material," Waste Manag., vol. 26, pp. 1277-1286, 2006.

[2] R. Cossu, "Groundwater contamination from landfill leachate: when appearances are deceiving!’ Waste Manag., vol. 33, pp. 1793-1794, 2013

[3] J. Cuevas, A. I. Ruiz, I. S. de Soto, T. Sevilla, J. R. Procopio, P. D. Silva, M. J. Gismera, M. Regadío, N. S. Jiménez, M. Rodríguez Rastrero, and S. Leguey, "The performance of natural clay as a barrier to the diffusion of municipal solid waste landfill leachates," J. Environ. Manag., vol. 95 , pp. S175-S181, 2012.

[4] D. E. Daniel, Geotechnical Practice for Waste Disposal, Chapman \& Hall, 1993.

[5] Y. E. A. Mohamedzein, A. A. Al-Rawas, M. Y. Al-Aghbari, A. Qatan, and A. H. Al-Rawas, "Assessment of crushed shales for use as compacted landfill liners," Engineering Geology, vol. 80, pp. 271-281, 2005.

[6] I. Ghorbel-Abid and M. Trabelsi-Ayadi, "Competitive adsorption of heavy metals on local landfill clay," Arab. J. Chem., 2011.

[7] N. Sánchez-Jiménez, M. J. Gismera, M. T. Sevilla, J. Cuevas, M. Rodríguez-Rastrero, and J. R. Procopio, "Clayey materials as geologic barrier in urban landfills: comprehensive study of the interaction of selected quarry materials with heavy metals," Appl. Clay Sci., vol. 56, pp. 23-29, 2012.

[8] Z. Li, Q. Xue, T. Katsumi, and T. Inui, "Electric-hydraulic-chemical coupled modeling of solute transport through landfill clay liners," Appl. Clay Sci., vol. 101, pp. 541-552, 2014.

[9] T. Chalermyanont, S. Arrykul, and N. Charoenthaisong, "Potential use of lateritic and marine clay soils as landfill liners to retain heavy metals," Waste Manag., vol. 29, pp. 117-127, 2009.

[10] F. M. Fransisca and D. A. Glatstein, "Long term hydraulic conductivity of compacted soils permeated with landfill leachate," Appl. Clay Sci., vol. 49 , pp.187-193, 2010
[11] Standard Methods for the Examination of Water and Wastewater American Public Health Association (APHA), Washington DC, 2005.

[12] S. Pal, K. Adhikari, S. Ghosh, and S. N. Mukherjee, "Characterization of subsurface water near an industrial wastewater disposal site," Inter. J. Earth Sci. Eng., vol. 04, no. 06, pp. 437-441, 2011.

[13] Guidelines for Drinking Water Quality: Health Criteria \& Other Supporting Information, 2nd ed, vol. 2, World Health Organization, Geneva, 1997.

[14] Methods of Test for Soils: Preparation of Dry Soil Samples for Various Tests, IS 2720, Part 1, 1983.

[15] Methods of Test for Soils: Determination of Water Content, IS 2720, Part 2, 1973.

[16] Test for Soils: Determination of Specific Gravity - Section 2: Fine, Medium and Coarse Grained Soils, IS 2720, Part III, 1980.

[17] Methods of Test for Soils: Grain Size Analysis, IS 2720, Part 4, 1985.

[18] Method of Test for Soils: Determination of Liquid and Plastic Limit, IS 2720, Part 5, 1985

[19] Methods of Test for Soils: Determination of Organic Matter, IS 2720, Part 22, 1972.

[20] Method of Test for Soils: Determination of pH Value, IS 2720, Part 26, 1987.

[21] Methods of Test for Soils: Laboratory Determination of Permeability, IS 2720, Part 17, 1986

[22] Determination of Shear Strength Parameters of Soil from Consolidated Undrained Triaxial Compression Test with Measurement of Pore Water Pressure, IS 2720, Part 12, 1981.

[23] Measurement of Swelling Pressure of Soils, IS 2720, Part 41, 1977.

[24] Classification and Identification of Soils for General Engineering Purposes, IS 1498-1970, 2002.

[25] P. V. Sivapullaiah, H. Lakshmikantha, and K. K. Madhu, "Geotechnical properties of stabilized Indian red earth," Geotechnical and Geological Engineering, vol. 21, pp. 399-413, 2003.

[26] M. R. Taha and M. H. Kabir, "Tropical residual soil as compacted soil liners," Environ. Geol., vol. 47, pp. 375-381, 2005.

[27] A. W. Skempton, "The colloidal activity of clays," in Proc. the Third International Conference on Soil Mechanics and Foundation Engineering, 1953, vol. 1, pp. 57-61.

[28] I. S. Oweis and R. P. Khera, Geotechnology of Waste Management, $2^{\text {nd }}$ ed, PWS Publishing Company, USA, 1998, p. 472

[29] D. E. Daniel and Y. K. Wu, "Compacted clay liners and covers for arid sites," J. Geotech. Eng. ASCE, vol. 119, no. 2, pp. 223-237, 1993.

[30] R. K. Rowe, R. M. Quigley, and J. R. Booker, Clayey Barrier Systems for Waste Disposal Facilities, E \& FN Spon Lond, 1995, p. 390.

[31] C. H. Benson and D. E. Daniel, "Influence of clods on hydraulic conductivity of compacted clay," J. Geotech. Engg. ASCE, vol. 116, no. 8, pp. 1231-1248, 1990.

[32] C. Sheu, T. T. Lin, J. E. Chang, and C. H. Cheng, "The feasibility of mudstone material as natural landfill liner," J. Hazard. Mater., vol. 58, pp. $237-247,1998$

[33] C. H. Benson and J. M. Trast, "Hydraulic conductivity of thirteen compacted clays," Clays Clay Min., vol. 43, no. 6, pp. 669-681, 1995.

[34] E. D. McBean, F. A. Rovers, and G. J. Farquhar, Solid Waste Landfill Engineering and Design, Prentice Hall PTR, New Jersey, 1995, p. 521.

[35] T. W. Lambe and R. V. Whitman, Soil Mechanics, John Wiley and Sons, Inc., 1969

[36] S. Pal, S. N. Mukherjee, and S. Ghosh, "Application of Hydrus 1D model for assessment of phenol-soil adsorption dynamics," Environ. Sci. Pollut. Res., 2014.

[37] T. Viraraghavan and F. M. Alfaro, "Adsorption of phenol from wastewater by peat, fly ash and bentonite," J. Hazard. Mater., vol. 57 pp. 59-70, 1998 .

[38] M. Djebbar, F. Djafri, M. Bouchekara, and A. Djafri, "Adsorption of phenol on natural clay," Appl. Water Sci., vol. 02, no. 02, pp. 77-86, 2012.

[39] V. R. Kiran and B. Chandrajit, "Simultaneous adsorptive removal of cyanide and phenol from industrial wastewater: optimization of process parameters," Res. J. Chem. Sci., vol. 01, no. 4, pp. 30-39, 2011.

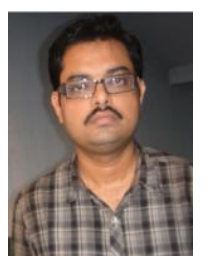

Supriya Pal was born on April 7, 1978 in Mankar, Burdwan, West Bengal, India. He graduated from the Department of Civil Engineering, North Bengal University in 2000 and received the master degree of civil engineering in 2002 from Jadavpur University.

$\mathrm{He}$ is currently an assistant professor at National Institute of Technology Durgapur, Department of Civil Engineering. He has 7 years' teaching and research experience in the fields of geotechnical and geo-environmental engineering 
and 5 years' industrial experience. His research spans are solute transport through porous media, landfill liner design, ground improvement and electrokinetic remediation of contaminated sites. He has directed and supervised numerous research studies and projects in the field of geotechnical and geoenvironmental engineering.

He also has 12 research publications in reputed national and international journals and conference proceedings.

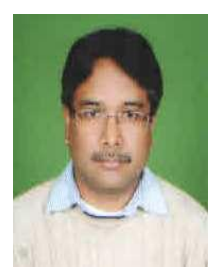

Kalyan Adhikari received the M.Sc. degree in 1991 and the Ph.D degree in 2003 both from the University of Burdwan, West Bengal, India.

$\mathrm{He}$ is currently an associate professor at National Institute of Technology Durgapur, Department of Earth and Environmental Studies. His research spans are groundwater occurrence, quality, subsurface migration of contaminants and remedies, contaminant removal by natural adsorbents, application of RS and GIS in Geoscience. He has published 25 technical papers in reputed national and international journals as well as conference proceedings.

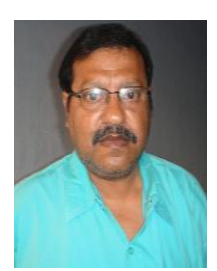

Somnath Mukherjee is a professor in the Department of Civil Engineering at the Jadavpur University, Kolkata, India. He holds a M.Tech. degree from IIT, Kharagpur for his work on 'emulsified oily wastewater' and a Ph.D degree from IIT, Kharagpur for the thesis with title "COD removal and denitrification in upflow anaerobic fixed film reactor". His major fields of interest span environmental engineering and geo-environmental engineering with specific research work undertaken in biological treatment of wastewater, adsorption technology for water treatment and pollutant migration through soil and ground water.

He reckons 25 years' research experience, 22 years' teaching experience in civil and environmental engineering and 8 years' industrial experience in project management and consultancy. He also has 75 journal publications and a total of 55 papers presented and published in proceedings of national and international conferences.

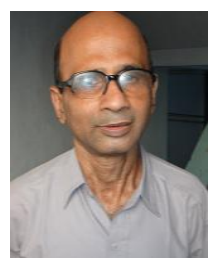

Sudipta Ghosh is a professor in the Department of Civil Engineering at the Jadavpur University, Kolkata, India. He holds a master degree of civil engineering and a Ph.D degree from Jadavpur University, Kolkata. His major fields of interest span geotechnical and geo-environmental engineering with specific research work undertaken in pollutant migration through soil and ground water.

He reckons 20 years' teaching and research experience in civil and geo-environmental engineering and 12 years' industrial experience. He also has 55 research publications in reputed national and international journals and conference proceedings. 